\title{
RECEPTOR ACTIVITY FOR PORCINE ENTEROVIRUSES IN PIG TISSUES
}

\author{
J. B. Derbyshire AND D. M. JesSETt* \\ Agricultural Research Council, Institute for Research on Animal Diseases, \\ Compton, Newbury, Berkshire
}

IN the study of the pathogenesis of porcine enterovirus infections the distribution of receptor activity for these viruses in pig tissues is of interest. This was investigated by measuring the in-vitro adsorptive capacity of tissue homogenates for 2 virus strains, Talfan and V13, that were selected as representatives of the 2 main groups of porcine enteroviruses found in Britain (Alexander and Betts, 1967). The results of some comparative studies with bovine tissues, and with a strain of Coxsackie B1 virus are also included.

\section{MATERIALS AND METHODS}

Stocks of the porcine enterovirus strains Talfan and V13 were prepared in secondary pig kidney-cell cultures, and titrated by plaque assay in the Stice pig kidney cell line (Derbyshire and Jessett, 1967). Coxsackie B1 virus (strain P.O.) was cultivated and assayed in HeLa cells by techniques similar to those used with the porcine enteroviruses. To avoid the presence of virus-neutralising antibodies tissues were collected, immediately after slaughter, from hysterotomy-derived, colostrum-deprived piglets or from colostrum-deprived calves, and a 20 per cent. (w/v) homogenate of each tissue was prepared as described by La Placa (1963). The homogenates were tested for adsorption of the appropriate virus by La Placa's method, residual infectivity of the sample being assayed by the plaque procedure in Stice cells or HeLa cells, with 4 plates per sample. The virus dose used was calculated to yield approximately 50 plaques per plate in the absence of adsorptive activity in the tissue homogenate. In each series of tests, virus controls were included, in which the tissue homogenate was replaced with balanced salt solution. The adsorptive activity of a tissue was expressed as the percentage reduction in plaque count of the adsorbed virus compared with the control sample. Ether treatments and centrifugation procedures on the tissue homogenates followed the techniques described by Kunin (1962).

\section{RESULTS \\ Adsorption of porcine enteroviruses by pig tissues}

Twenty per cent. homogenates were prepared from the tissues of 20 piglets aged between 1 and 31 days, and tested for adsorption of Talfan and V13 viruses. The results of these experiments are summarised in table I (columns 2 and 3). There were no significant age differences within the age-range tested, and only minor differences in adsorptive capacity of the various tissues were observed. A further attempt was made to detect significant differences in adsorptive power of the tissues by testing serial two-fold dilutions of the

Received 14 Mar. 1969; accepted 6 May 1969.

* Present address: E.A.V.R.O., P.O. Kabete, Kenya.

J. MED. MICROBIOL.-VOL. 2 (1969) 
20 per cent. homogenates prepared from one of the pigs. The results of this test are also shown in table I (columns 4 and 5). Most of the homogenates adsorbed

\section{TABLE I}

Adsorption of porcine enteroviruses by pig tissues

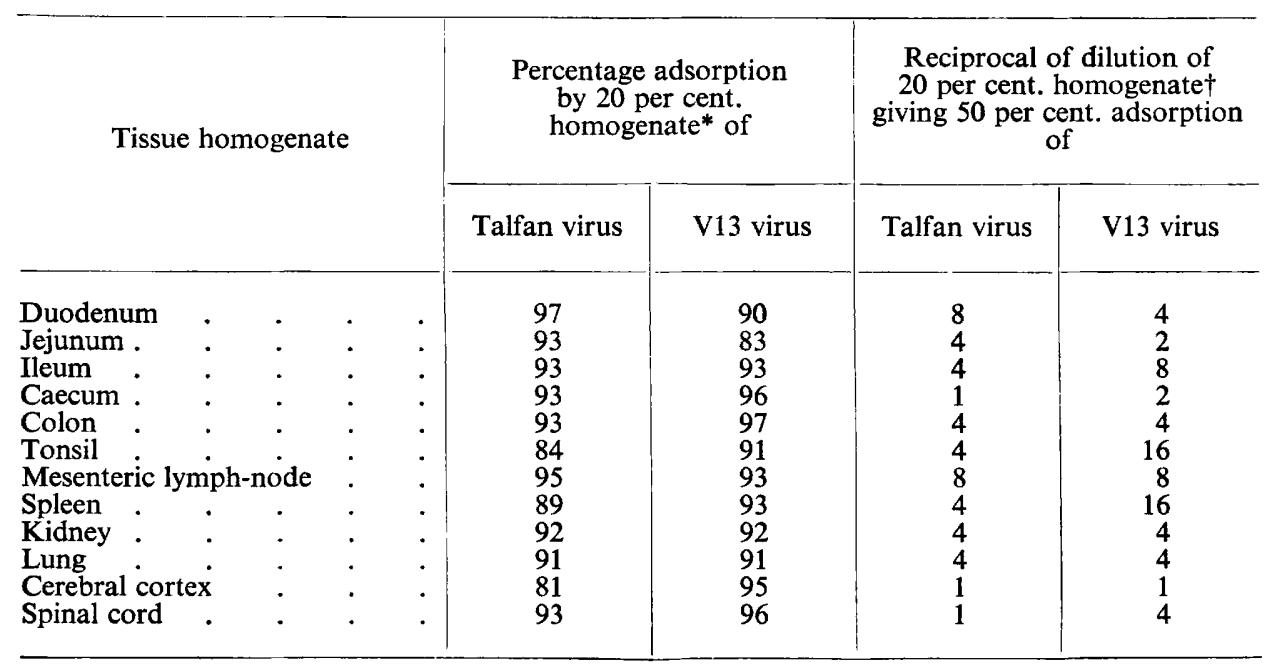

* Mean values from tissues of 20 piglets.

$\dagger$ From single animal.

TABLE II

Adsorption of porcine enteroviruses by calf tissues

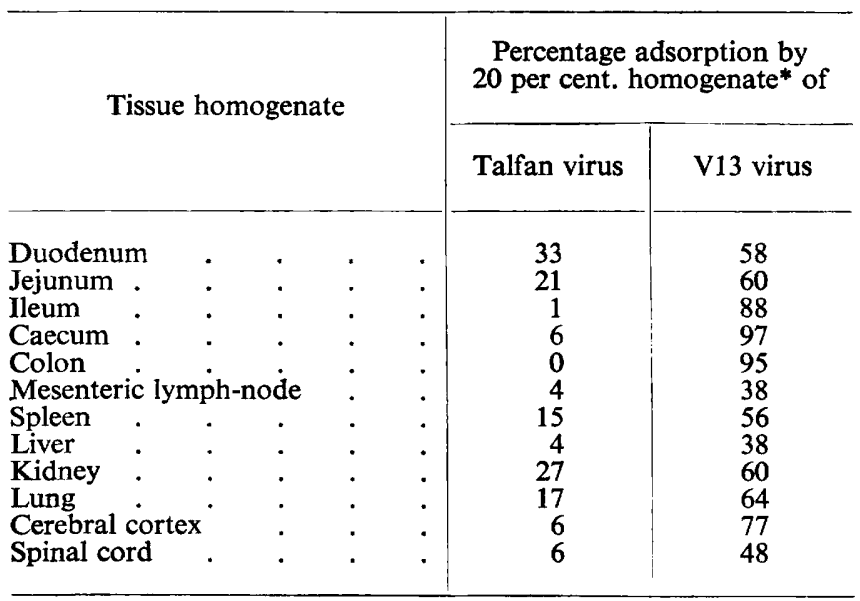

* Mean values from tissues of 5 calves.

at least 50 per cent. of the virus infectivity when diluted 1 in 4 , but some homogenates adsorbed 50 per cent. when diluted 1 in 16 . In additional experiments, 20 per cent. tissue homogenates were tested for adsorption of up to 5 times the 
usual virus concentrations, and the results obtained were similar to those with the normal virus dose. Finally, loss of the adsorptive capacity of the tissue homogenates after treatment with ether, or after centrifugation, was demonstrated.

\section{Adsorption of porcine enteroviruses by calf tissues}

Homogenates of the tissues listed in table II were prepared from each of 5 calves aged between 2 and 4 days, and tested for adsorption of Talfan and V13 viruses. There was no significant adsorption of Talfan virus by any of the

TABLE III

Adsorption of Coxsackie BI virus by pig and calf tissues

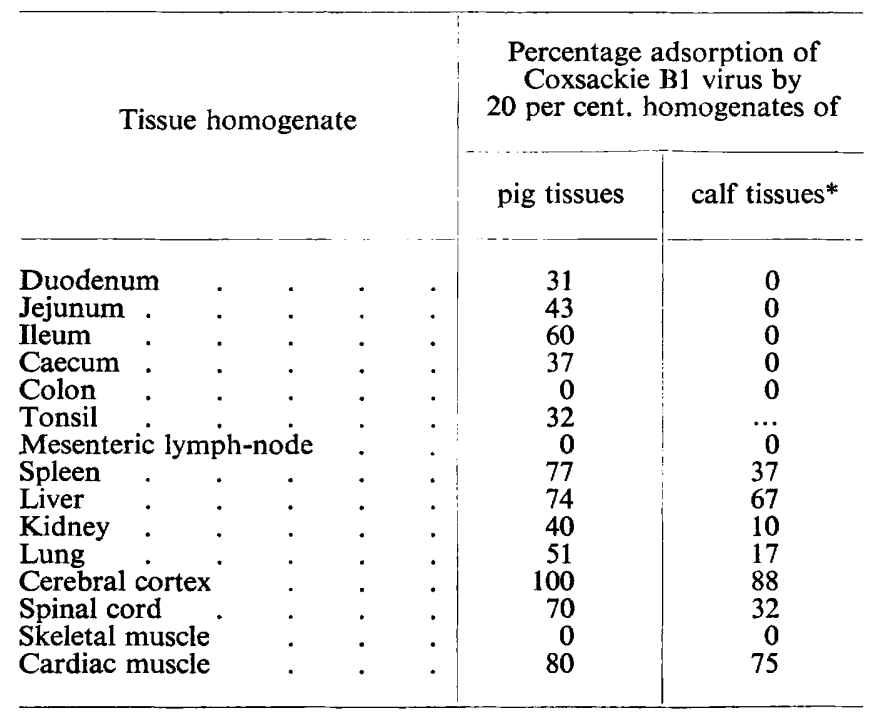

* Mean values from tissues of 2 calves.

... Not tested.

tissues, but though most of the tissues adsorbed relatively little V13 virus, the latter was strongly adsorbed by ileum, caecum and colon. The adsorptive capacity of these tissues for V13 virus was removed by ether treatment or centrifugation.

\section{Adsorption of Coxsackie B1 virus by pig and calf tissues}

Homogenates of the tissues obtained from a 20-day-old piglet and from two 4-day-old calves were tested for adsorption of Coxsackie B1 virus (see table III). Most of the tissues from either species failed to adsorb significant amounts of the virus. However, liver, cerebral cortex and cardiac muscle of both pig and calf adsorbed significant amounts, and in addition pig ileum, spleen and spinal cord showed some adsorption of the virus. The adsorptive capacity of the tissues for Coxsackie B1 virus was removed by ether treatment or centrifugation. 


\section{Discussion}

Our object was to determine to what extent tissue tropisms of porcine enteroviruses could be explained on the basis of the relative abundance of receptor activity in the various tissues of the host. Observations on naturally infected (Derbyshire, Clarke and Jessett, 1969) and experimentally infected piglets (briefly reviewed by Kasza, Holman and Koestner, 1967) indicate that the principal site of enterovirus replication is the intestinal tract. Though in our present experiments we found abundant receptor activity in the intestinal tract, many other tissues also adsorbed the enteroviruses under test. For V13 virus, receptor activity appeared to be most abundant in lymphoid tissues. Much has been published on cellular susceptibility to human enteroviruses, and this literature has been reviewed by Kunin (1964). Holland (1961) found that primate tissues and organs in which a virus does not multiply extensively showed little receptor activity for that virus, but Kunin and Jordan (1961) did find virusbinding activity in insusceptible tissues and organs. Similarly, La Placa (1963) found that bovine enteroviruses were adsorbed by liver, kidney and lung in addition to intestinal and nervous tissue.

We endeavoured to confirm the specificity of the widespread receptor activity in pig tissues in several ways. Firstly, we demonstrated that the adsorbing capacity of the tissue homogenates was removed by treatment with ether, or by centrifugation. Secondly, we showed that, with certain exceptions, the test viruses were not significantly adsorbed by bovine tissues, and thirdly that most of the pig tissue homogenates failed to adsorb significant amounts of Coxsackie B1 virus.

The high adsorptive capacity of bovine ileum, caecum and colon for porcine enterovirus V13 suggests the possibility that this virus may be capable of infecting the intestinal tract of the calf. In a limited investigation (unpublished data) we have not found antibodies to V13 virus in bovine sera, but the experimental infection of calves with this virus has not been attempted. Similarly, it was of interest that Coxsackie B1 virus was adsorbed by both bovine and porcine brain and cardiac muscle, particularly in view of the production of encephalitis and myocarditis by Coxsackie B viruses in other species (Andrewes and Pereira, 1967). The isolation of Coxsackie B viruses from pigs has not been reported, but Verlinde and Versteeg (1958) isolated Coxsackie A5 virus from pig lung, and produced pneumonia on experimental inoculation of the virus in pigs. Group B Coxsackie viruses produce cytopathic effects in cultivated pig kidney cells (Guerin and Guerin, 1957; Lenahan and Wenner, 1960), and the susceptibility of calves and piglets to experimental infection with these viruses would be worth investigating.

\section{SUMMARY}

Receptor activity for the porcine enterovirus strains Talfan and V13 was found in homogenates of various tissues prepared from each of 20 piglets. Homogenates of the same tissues from 5 calves did not adsorb Talfan virus, but high adsorptive capacity for V13 virus was present in calf ileum, caecum and 
colon. Coxsackie B1 virus was adsorbed by homogenates of piglet and calf liver, cerebral cortex and cardiac muscle, and by piglet ileum, spleen and spinal cord. The adsorptive capacity of the homogenates was removed by ether treatment or centrifugation.

The porcine enteroviruses were obtained from Professor A. O. Betts, Royal Veterinary College, and the Coxsackie B1 virus was obtained from the Central Public Health Laboratory through the co-operation of Miss P. M. Davis. We wish to acknowledge the technical assistance of Mr Alan Collins, who prepared the cell cultures, and of Mrs Susan Arkell.

\section{REFERENCES}

AleXAnder, T. J. L., AND BetTs, A. O. . 1967. Res. Vet. Sci., 8, 330.

Andrewes, C. H., and Pereira, H. G. . 1967. Viruses of vertebrates, 2nd ed., London, p. 11.

Derbyshire, J. B., Clarke, M. C., and 1969. J. Comp. Path., 79, 97.

JESSETT, D. M.

Derbyshire, J. B., AND Jessett, D. M. . 1967. Ibid., 77, 237.

Guerin, L. F., ANd Guerin, M. M. . - 1957. Proc. Soc. Exp. Biol. Med., 96, 322.

Holland, J. J. . . . . . . . . . 1961. Virology, 15, 312.

Kasza, L., Holman, J., And Koestner, 1967. Amer. J. Vet. Res., $28,461$.

A.

Kunin, C. M. . . . . . . . . . . . . 1962. J. Immun., 88, 556.

" . . • . . . . . 1964. Bact. Rev, 28, 382.

Kunin, C. M., ANd Jordan, W. S., JR . 1961. Amer. J. Hyg., 73, 245.

La Placa, Michele . . . . . . 1963. Nature, Lond., 199, 1211.

Lenahan, Margaret F., and Wenner, 1960. J. Infect. Dis., 107, 203.

H. A.

Verlinde, J. D., And Versteeg, J. 1958. Tijdschr. Diergeneesk., 83, 459. 